\title{
Recent Research on the Parietal Lobes, Proprioceptiv Sensibilities and Tactile and Kinesthetic Abilities in Speech Production
}

RUTH M. CLARK, Ph.D.*

\section{INTRODUCTION}

At the University of Denver wc have been trying through research to understand more adequately the part the parietal lobes and proprioceptive sensibilities play in speech production, and to discover if the kinesthetic and tactile abilities of children having "functional" articulatory problems differ from these abilitics for normal speaking children.

A number of requests have been received asking for data on the above-mentioned researches. The purpose of this article is to review briefly these studies and give references for the benefit of interested colleagues.

It is planned that a more adequate report on each study will soon be published, but for the present this overview will give the data requested so those interested can obtain the studies through inter-library loan. It is also hoped that some of the proposed topics listed in the dissertations for further rescarch along these lines will receive attention.

Three studies will be reviewed in the order in which they werc completed.

\section{THE ROLE OF THE PARIETAL LOBES IN SPEECH (3). IMPORTANCE OF THE STUDY}

For years the standard or acceptable approaches for speech training and speech re-training have been the use of sight and hearing. The study under review undertook to determinc if, in addition to visual and auditory training, other sensory approaches existed or were feasible to use for speech lcarning.

A study of the opinions of a number of individuals in the speech field, as well as neurologists, indicated that the use of a third sensory avenue, i.e., the stimulation of the tactile and proprioceptive sense's, would be another approach to usc in speech therapy.

The literature in the fields of physiology, neurology and physiological psychology was reviewed to discover the anatomical structures

\footnotetext{
* Ruth M. Clark (Ph.D., University of Southern Californio, 19431 is the Director of the Speech Clinic and Professor of Speech, University of Denver, Denver 10, Colorodo.
}

which might be used in the teaching of a motor pattern through tactile and/or kinesthetic sensation. In addition to the anatomy of the somesthetic structures, their function was also discussed.

In dealing with the "doubly-handicapped" person where the hard-of-hearing individual may miss all or part of the auditory stimulation, or the individual whose sight is impaired may miss most of the visual stimulation, "the urgency of investigating other approaches to speech learning is obvious." $(3, \mathrm{p} .3)$.

\section{PURPOSE OF THE STUDY}

The study was predicated upon the belief that there exists, in addition to visual and auditory avenues, other sensory approaches for use in learning and re-learning specch. The author investigated the possibility of utilizing cutaneous and kinesthetic sensations in the creation, or the improvement of motor patterns for speech. Specifically he tried to answer the following questions:

1. What physiological mechanisms does this tactile and/or kinesthetic approach employ?

2. How do these physiological mechanisms function?

3. What cortical receptors receive these tactile and kinesthetic cue messages?

4. How do these cortical receptors function in possibly initiating, terminating, accelerating, or decelerating motor nerve messages destined for the peripheral specch mechanism?

5. How may this "new" sensory approach function in the learning of typical English specch sounds?

\section{RESULTS}

The results of the investigation indicated that it is generally believed that numerous extcroceptors and proprioceptors exist in the peripheral speech musculature. It is also belicved that somesthetic pathways to the parietal lobe are cmployed by sensations resulting from touch, pressure and movement stimulation of the exteroceptors, and musclc-stretch and muscle-contraction stimulation of the proprioceptors. 
When the somesthetic spike potential reaches the parietal lobe it appears to possess unique opportunities not available to visual or auditory spike potentials for initiating, facilitating, or inhibiting the motor movement patterns essential to speech production. (3, p. 116.)

Three anatomical characteristics of the parietal and frontal lobes provide these "unique opportunities". The author concluded that the nature of these peculiarly adequate sensori-motor connections, "enable the parietal lobes to play a significant role in laying down a cortical mnemonic neutral trace", which facilitates and synchronizes muscle movement patterns essential to speech.

It was suggested that for the best results in securing correct motor patterns for speech, auditory and visual stimulations should be integrated with the "significant potential of somesthetic stimulations." (3, p. 149.)

\section{THE ROLE OF PROPRIOCEPTIVE SENSIBILITIES IN SPEECH PRODUCTION (1)}

\section{IMPORTANCE OF STUDY}

Human speech is made possible by proper integration of highly complex neuromuscular reactions of almost the entire organism. In the production of speech, synergy and synthesis of muscular patterns are important. Both synergy and synthesis have as their basis proprioceptive sensibilities. "One would be safe in saying that all speech involves muscle activity and all muscle activity involves proprioception". (2, p. 2.)

The sensibilities arising from the deeper tissues of the body, principally from the muscles, ligaments, bones, tendons, and joints, are generally considered to be the proprioceptive sensibilities.

The study under discussion did not attempt to advance the sense of proprioception to the exclusion of the other senses but rather to point out that the proprioceptive sense is an outstanding supplement to the other senses.

\section{PURPOSE OF THE STUDY}

According to the author the purpose of this study was two-fold:

1. To discover as nearly as possible the role of proprioception sensibilities in speech production as shown by correlation of information from the areas of physiology, neuro-anatomy, and physical and speech pathology.
2. To attempt to bring together a body of knowledge which will further the understanding of how proprioceptive sensibilities can be utilized in therapeutic procedures. It is suggested that these findings be tested in further studies. (2, p. 9.)

\section{RESULTS}

In the individual with a normal central nervous system, proprioceptive control is of such an automatic nature that it is usually given little consideration. "Because of this lack of recognition and the apparent subservient status of proprioception to the other sense, which are often considered of greater importance, this sense is neglected in the training programme of those who do not have normal speech". (2, p. 174.)

Research in the area of physical medicine has shown that these deep sensibilities can be stimulated to enhance the habilitation and rehabilitation of those suffering from neuromuscular disorders.

Physical therapy has used various modalities successfully in rehabilitation techniques. Dr. Dittman (2) analyzed these modalities in terms of their effectiveness in setting up a "physical climate for speech", and in terms of their effectiveness in establishing mnemonic memory patterns in the cortex. Several proprioceptive therapeutic techniques advanced by persons interested in neuromuscular rehabilitation were also presented. The author also "set up" a proprioceptive therapeutic programme consisting of three stages of progression. The majority of the proprioceptive modalities were considered to be applicable to the speech mechanism per se. However, the tentative conclusions arrived at through the study indicate that more functional research is needed to substantiate the concepts presented. The modalities discussed should supplement the conventional speech therapy techniques, rather than supplant them.

\section{A STUDY OF LINGUAL SENSORY CHARACTERISTICS ACCOMPANY- ING "FUNCTIONAL" DISORDERS OF ARTICULATION (2).}

\section{IMPORTANCE OF THE STUDY}

It is generally conceded that about seventy-five per cent. or more of the speech problems encountered are disorders of articulation, and therefore occupy the largest part of the speech therapist's load. In the majority of these cases no apparent cause is found for the faulty articulation and they are referred to as "functional". 
Many important studies have been performed in the area of "functional" articulatory speech problems, but much more needs to be carried on if we are to understand this large group of speech disturbances. Research has produced a multiplicity of causal factors, but "conspicuous because of its almost complete absence from research studies is the mention of tactile and/or kinesthetic sense deviations as possible etiological factors". (2, p. 5.)

\section{PURPOSE OF THE STUDY}

Dr. Larson (2) wondered if the ability to "feel" existed to the same extent among children with functional articulatory disorders as among children with normal speech. He stated his problem as follows:

The purpose of this study was to discover if functional articulatory subjects tend to have different kinesthetic and tactile ability from normal subjects as shown by testing bodily cxtremities (fingers) and an oral midline area (tongue). (2, p. 1.)

\section{PROCEDURE.}

Three tests were developed and administered to sixty elementary and junior high school children. The experimental group was composed of thirty subjects with functional articulatory disorders. The control group of thirty was matched on the basis of chronological age, sex, intelligence rating, economic status, and family sibling pattern. The three tests developed were administered to both groups. The tests measured the ability to judge size of objects manually; size of objects orally; and size of small openings with the tip of the tongue.

\section{RESULTS.}

The data indicated that neither group showed any consistent superiority over the other when discriminating between sizes of objects manually. The control group excelled the experimental group somewhat in judging between sizes of objects lingually; however, it was not to any acceptable degree of reliability. On the test that compared the two groups on their ability to "discriminate differences between small holes with the tip of the tongue, however, the control group's superiority was decidedly significant beyond the O.1. per cent. level." (2, p. 116.)

The author was extremely cautious in evaluating his results and said, though many children with functional articulatory problems exhibited a lower ability to make fine discriminations with the tongue-tip, no inference was given that tactile deficiency of the tongue-tip was necessarily a fundamental cause of articulatory disorders. "At best, this particular type of deficiency may be considered as one factor within a complexity of etiological patterns". (2, p. 134.)

One of the outstanding contributions of this research was the chapter on suggestions for further study and the ingenuity and meticulousness used in devising the tests.

\section{REFERENCES}

1. Ditlman, Helen H., "The Role of Proprioceptive Sensibilities in Speech Production." Unpublished Doctor's dissertation, University of Denver, Denver, June, 1955, 231 pp.

2. Larson, M.H., "A Study of Lingual Sensory Characteristics Accompanying 'Functional' Disorders of Articulation". Unpublished Doctor's dissertation, University of Denver, Denver, November, 1955, 149pp.

3. Tyson, J. D., "The Role of the Parietal Lobes in Speech". Unpublished Doctor's dissertation, University of Denver, Denver, August, 1954, 149pp. 